\title{
A geração 68 no Congresso Nacional: Ideologia e
}

\section{comportamento legislativo ${ }^{1}$}

\author{
Maria Francisca Pinheiro Coelho ${ }^{2}$
}

e Vitor Leal Santana ${ }^{3}$

Resumo: No mundo todo, a década de 1960 caracterizou-se pelos movimentos de juventude. E se houve um momento que correspondeu a um levante mundial simultâneo foi sem dúvida 1968, o ano da agitação estudantil por excelência. Mais de 40 anos depois, transformações sociais e políticas importantes alteraram normas e valores sociais, reordenando-os em função de novos desafios e perspectivas. O trabalho examina o comportamento atual da geração 68 no Brasil, pelo que seus membros defendem politicamente. A amostra considera os indivíduos que estiveram na universidade em 1968, o lócus dos conflitos naquele momento, e que ascenderam ao Congresso Nacional no pós-autoritarismo. Com base no perfil daquela geração, o objetivo do texto é avaliar de que forma sua identidade política se diluiu frente às mudanças institucionais, verificando ainda o impacto das construções ideológicas sobre o comportamento legislativo dos líderes estudantis que assumiram uma posição de destaque na política nacional. Os dados mostram que as ideologias e utopias de outrora, além de se reorientarem em torno de novos valores e perspectivas, se adequaram aos desafios e ao contexto sociopolítico do momento.

Palavras-chave: geração, ideologia, utopia, comportamento legislativo, Congresso Nacional
1. Trabalho apresentado no XIV Congresso Brasileiro de Sociologia, na mesaredonda "A atualidade do conceito de geração na pesquisa sociológica", Rio de Janeiro, julho de 2009. Os resultados apresentados fazem parte da pesquisa "O comportamento político atual da geração de 1968", com bolsa de Produtividade de Pesquisa do CNPq. Somos gratos à Juliana Brandt Guedes e Jeferson Martins de Castro (CNPq/UnB-PIC/20072008) pela ajuda na coleta dos dados.

\section{Doutora em} sociologia e professora da Universidade de Brasília. coelhofrancisca@gmail.com.

3. Mestrando em ciência política, Instituto de Ciência Política da Universidade de Brasília. santana.vitor@gmail.com. 


\section{Introdução}

Na realidade, se acreditamos já possuirmos a verdade, perderemos o interesse em descobrir as próprias intuições que nos conduziram a uma compreensão aproximada da situação.

\section{Karl Mannheim}

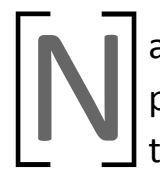

a década de 1960, os movimentos de juventude se propagaram pelo mundo e fizeram de 1968 um ano marcado por profundas transformações culturais, entrando para a história por suas ideologias e utopias. Os anseios revolucionários tomaram conta das manifestações que açambarcaram um conjunto amplo de reivindicações. Os anos 1960 foram um simulacro de revolução que levou a reformas sociais que seriam percebidas apenas no longo prazo (Rotman, 2008: 38). O questionamento do status quo e a ênfase na defesa dos direitos civis se constituíram o elo de união entre os movimentos sociais naquele momento. Tinham como traço característico a transgressão de padrões e valores estabelecidos.

Na época, no Brasil, regido pelo regime militar (1964-1985), o clima era de repressão. No país, as manifestações ao longo da década de 1960 se expressavam particularmente no movimento estudantil, mas abarcavam também o meio cultural, intelectual e artístico. Com a intervenção militar, apesar da reformulação das entidades estudantis e da suspensão das atividades políticas, os estudantes representados pela União Nacional dos Estudantes (UNE), entidade tornada ilegal, reergueram o movimento nacionalmente. Reativaram os diretórios acadêmicos e os diretórios centrais dos estudantes - os DCEs - e organizaram passeatas e manifestações em todo país por mais verbas e mais vagas nas universidades públicas.

O movimento, inicialmente de caráter reivindicativo, foi ocupando as ruas das grandes cidades e transformando-se em uma luta política contra o regime militar. Às palavras de ordem específicas uniram-se à de "Abaixo a ditadura". O movimento tornara-se, assim, protagonista de uma insatisfação nacional em um momento em que os sindicatos dos trabalhadores estavam sob forte repressão e os partidos políticos tradicionais haviam sido dissolvidos e substituídos por agremiações criadas pela ditadura militar, a Aliança Renovadora Nacional (Arena) e o Movimento Democrático Brasileiro (MDB). 
Com o aumento da repressão ao movimento estudantil, principalmente após a passeata dos 100 mil, no Rio de Janeiro, em 26 de junho de 1968, o movimento passou a adotar novas formas de luta, na medida em que as passeatas eram dissolvidas com violência. Sob grande influência de grupos e organizações de esquerda que atuavam na clandestinidade, boa parte da liderança estudantil passou a subestimar as frentes de luta legal, acreditando que o caminho para as mudanças pretendidas seria a revolução socialista.

O Ato Institucional n. 5, promulgado em 13 de dezembro, de 1968, foi um marco na institucionalização da repressão, com a cassação de direitos políticos e a implantação de um Estado de exceção. Com o Decreto 477, instrumento que institucionalizou a repressão nas universidades, líderes estudantis foram expulsos e perseguidos, muitos deles presos e mortos sob tortura (Arns, 1985).

Segundo Irene Cardoso (2005), os movimentos estudantis, no final da década de 1960, transgrediram as formas tradicionais de ação política que caracterizava a esquerda até então, sendo reorientado em torno de alternativas políticas para as ideologias da época. As reivindicações daquele momento iam ao encontro das utopias da juventude na época. ${ }^{4}$

Existia um ambiente favorável à organização de movimentos de esquerda revolucionários, dispostos a questionar a ordem social e política. A divisão do mundo em duas super potências - os Estados Unidos e a União Soviética - e as guerras de libertação existentes fortaleciam as ideologias de esquerda que defendiam o socialismo, como modelo alternativo ao capitalismo. As aspirações por um mundo melhor, o desejo de mudanças profundas na sociedade e o comportamento subversivo revestiram a geração 68 de uma imagem heróica, pois se vivia em uma época de grandes rupturas, transformações sociais e políticas. ${ }^{5}$

Mais de 40 anos depois das barricadas de Paris, das manifestações contra a Guerra do Vietnã e da passeata dos 100 mil, no Brasil, o que restou de herança do talvez mais polêmico ano do século XX? Muitos dos líderes da geração 68, no país, com o fim do regime ditatorial e a consolidação democrática, tornaram-se figuras de destaque na política nacional, alcançando um alto grau de influência no processo político. A ideologia que sustentava o pensamento revolucionário dos jovens naquele momento se esvaiu, ou pelo menos tomou outras formas, não sendo capaz de explicar a dinâmica atual da sociedade.
4. Ann Mische (1997) compara os anseios da geração de 1968 e da geração dos anos 1990, no Brasil, que foi às ruas e pediu o impeachment de Collor.

Na década de 1960, o desejo era por mudanças na universidade no meio estudantil e, em uma perspectiva mais global, de mudanças sociais, econômicas e políticas.

Na década de 1990, devido ao novo ambiente políticoinstitucional, lutavase contra a corrupção e com ideais voltados para o reforço da cidadania, valor fundamental da Constituição de 1988.

5. De acordo com Irene Cardoso (2005), essa imagem contribuiu para uma idealização da geração 68 e acabou pesando de forma desmedida sobre as gerações subsequentes. 
O objetivo deste texto é analisar, a partir de dados empíricos, o comportamento político atual da geração 68 no Congresso Nacional, na 52a legislatura (2003-2007).

Em 2002, a eleição para Presidência da República do ex-líder metalúrgico, Luiz Inácio Lula da Silva, do Partido dos Trabalhadores (PT), simbolizou a chegada ao poder daquela geração. Lula vinha de outra trajetória, as greves dos operários metalúrgicos de São Paulo, no final da década de 1970, mas a vitória do PT, partido que abriga setores expressivos daquela geração, foi interpretada como o fim de um ciclo iniciado em 1968. Naquela época, a geração 68 tinha em média 22 anos e nessa legislatura 57 anos.

Líderes estudantis chegaram ao topo do poder, com grande influência sobre o processo político-decisório. Mesmo sendo o pensamento político multifacetado, supõe-se existir algum núcleo comum, que dê unidade ao grupo e que tenha restado como traço de distinção daquela geração.

No caso da representação de um grupo ou de uma geração no parlamento, busca-se a identificação de traços remanescentes de uma história comum. Por outro lado, indaga-se também em que medida os seus representantes podem constituir uma geração no presente, em termos sociológicos, de uma posição social e de um comportamento semelhante.

\section{O conceito de geração}

O fenômeno biológico, o tempo cronológico e a localização são elementos constitutivos do conceito de geração. Porém, esses fatores por si só não explicam o fenômeno social "geração" que supõe a existência da interação social e a resposta coletiva a motivações, tendências ou correntes sociais. A geração como fenômeno social representa uma espécie particular de identidade de posição, que se expressa no modo como certos modelos de pensamento e experiência tendem a ser trazidos à existência dos indivíduos.

Ao se deter sobre o tema, Mannheim (1993) circunscreveu o conceito de

6. Que não se resume à mera contemporaneidade cronológica. geração a um conjunto de fatores de ordem qualitativa, como o tempo interior vivenciado, a contemporaneidade, ${ }^{6}$ o destino coletivo, que podem ser traduzidos na expressão "ser com o outro". A maioria dos homens pertence a uma determinada corrente de seu tempo, mas o espírito do tempo é fracionado. 
Diferentes gerações vivem no mesmo tempo e pessoas vivem eras subjetivas qualitativamente diferentes. Para o autor, as noções de vivência e destino coletivo são essenciais no conceito sociológico de gerações:

El individuo particular se forma, ante todo, con las influencias y las corrientes espirituales contemporâneas, que moran precisamente en aquellos círculos vitales con los que hay que contar desde un punto de vista sociológico. Esto quiere decir, para empezar, que al individuo no le afecta ni le atrae en absoluto la globalidade del "espíritu del tiempo", sino sólo aquellas corrientes de su tiempo que, tanto tradicional como actualmente, están presentes en su entorno (idem: p. 236).

A geração, como fenômeno social, se constitui com base em uma vivência comum. Daí a adequação do uso do conceito ao fenômeno das mobilizações em 1968. A "geração 68" ficou sendo conhecida como tal pelas marcas, atitudes e visões de mundo da juventude naquele momento. Para análise daquele período específico, da chamada rebelião de juventude, o conceito de geração se apresenta apropriado.

De acordo com Mannheim, para uma visão mais completa da problemática das gerações, é fundamental uma clarificação sociológica da distinção entre as categorias localização de geração (a posição social), geração como realidade (o destino coletivo) e unidade de geração (grupos identitários dentro de uma mesma geração). Nesse sentido, o fenômeno social geração representa uma espécie particular de identidade de posição, que compreende grupos mergulhados num processo histórico-social.

Não é o grupo social, embora possa ser em alguma situação, mas a posição social o suporte para se estudar o problema das gerações. Mais do que pertencer a um grupo, a posição de geração se define por uma semelhança de comportamento, pela consciência de pertencimento a uma tendência.

A posição social dos indivíduos nascidos em um mesmo tempo cronológico não seria dada apenas pela possibilidade de presenciarem os mesmos acontecimentos ou vivenciarem experiências comuns, uma vez que a idade seria apenas um aspecto formal. Segundo Mannheim, indivíduos que pertencem à mesma geração, que partilham do mesmo ano de nascimento, estão ligados a uma posição comum na dimensão histórica do processo social, mas isso não explicaria o fenômeno completamente. 
O autor se apoia em Pinder, da corrente histórico-romântica alemã, para mencionar a não contemporaneidade do contemporâneo, ou seja, o fato de indivíduos, mesmo vivendo o mesmo processo histórico e social, não compartilharem das mesmas normas e valores. Pessoas convivem com outras da mesma idade e de diferentes idades, em uma variedade de possibilidades de experiências. Para cada uma o mesmo tempo é diferente, representa um momento distinto de seu eu.

A geração seria fruto, sobretudo, do fato de indivíduos processarem esses acontecimentos com base em referências comuns que orientariam seus comportamentos (Weller, 2007). A localização de geração pode também se expressar - como ocorreu em 1968 - pela comunhão de localização de uma geração, isto é, mesmo quando distantes grupos se integram em experiências comuns. A experiência de comunhão de localização é um fenômeno cada vez mais frequente no contexto da globalização e da comunicação virtual.

A geração como realidade, por seu lado, precisa mais do que uma mera copresença em um contexto histórico e social. É necessário outro nexo concreto para que a geração se constitua como realidade. Esse vínculo adicional poderia ser descrito como a adoção de um destino comum, a partir de um laço concreto entre seus membros, pelo fato de estarem todos expostos aos sintomas sociais e intelectuais de um mesmo processo de mudança social.

Enquanto a simples localização comum de uma geração possui apenas um significado potencial, uma geração como realidade é constituída quando contemporâneos semelhantemente localizados ou em uma comunhão de localização participam de um destino comum e das ideias e conceitos que, de algum modo, estão ligados ao seu desenrolar. Ser contemporâneo cronologicamente só se torna sociologicamente significante se compreende também a participação nas mesmas circunstâncias sociais e históricas. Assim, só falamos de uma geração como uma realidade quando se cria um laço concreto entre os seus membros.

De uma posição social comum podem surgir particulares unidades de geração, que significam valores e práticas sociais distintas, apesar de se situarem em um mesmo processo histórico. Assim, dentro de qualquer geração, podem existir várias unidades de geração diferentes, ou mesmo antagônicas. Pode-se ter uma geração que se subdivide em várias unidades de geração. Uma mesma geração pode conter diferentes unidades de geração e mesmo com posições opostas: conservadores e revolucionários: 
A unidade de geração representa um laço mais concreto do que a geração real enquanto tal: "Fazem parte da mesma geração real os jovens que experimentam os mesmos problemas históricos concretos; e constituem unidades de geração separadas aqueles grupos que dentro de uma mesma geração real trabalham o material da sua experiência comum de modos específicos diferentes" (Mannheim, 1951: 154).

Ao tomar a geração 68 como exemplo, dela fazem parte os diferentes segmentos jovens que vivenciaram os acontecimentos daquele período. As unidades de geração têm suas próprias enteléquias (estilos, fins). Mas estas enteléquias não podem ser compreendidas dentro de si mesmas, precisam ser consideradas dentro da estrutura mais larga do Zeitgeist - o espírito de uma época.

Depende de uma série de fatores socioculturais saber se os impulsos de uma geração seguirão unidades distintas de estilo ou se continuarão latentes. Os jovens não são progressistas nem conservadores por natureza, mas possuem uma potencialidade sujeita a novas orientações, por sua própria condição social, de maior desprendimento em relação ao status quo.

O movimento de juventude dos anos 1960 queria construir um mundo meIhor, uma nova sociedade que, de preferência, fosse socialista.

As lutas "revolucionárias" da geração dos anos de 1960 tinham em comum o questionamento da situação presente e o objetivo de uma transformação social (Cardoso, 2005: 96).

Os jovens daquela geração davam a vida por um mundo melhor, mais justo e igualitário. Motivados pelas ideologias da época, chegaram mesmo a assumir como libertários modelos autoritários de sociedade (Coelho, 2006). As lutas por justiça social e por uma nova ordem política, além de ações de contracultura típicas de movimentos libertários, eram as bandeiras da juventude naquele momento (Ventura, 1988).

Não foram todos os jovens da geração 68 que se engajaram nas lutas revolucionárias do período, apesar de ser esse o espírito predominante da época. A geração 68 no Brasil viveu a polarização entre duas unidades de geração distintas: aqueles que participaram do movimento estudantil e os que não participaram. 
O movimento estudantil assumiu uma natureza política contestadora. Entretanto, os jovens daquela geração, apesar de partilharem de um processo histórico comum, deram respostas intelectuais e políticas distintas, formando unidades geracionais diferentes, principalmente a partir da participação ou não no movimento estudantil. O conceito de unidade de geração torna-se útil na análise dos dados da pesquisa, na medida em que apenas parcela dos estudantes de 1968 aderiu ao movimento estudantil.

\section{Ideologia e utopia}

Ao tentar comparar o comportamento de uma geração em dois momentos histórico-sociais tão diversos, dificuldades analíticas se apresentam. As pessoas são as mesmas, mas vivenciam um momento distinto de vida e uma situação política substancialmente diferente. A existência que cerca um indivíduo jamais constitui uma existência em si, mas é sempre uma forma histórica e concreta de existência social. Nesse sentido, os elementos ideológicos e utópicos não ocorrem separadamente do processo histórico.

Vistas as ideologias e utopias como produções sociais, a relação dessas ideias com o mundo real é imanente, mesmo sendo ideias que transcendem à realidade. Dessa forma, a possibilidade de mudanças nesses ideais também é real e concreta, pela própria dinâmica da sociedade.

Ora vislumbrando revoluções sociais, ora lutando para manter o status quo, a sociedade orienta-se em torno de ideias e valores distintos. O desafio na análise da ideologia e da utopia é a busca da compreensão da realidade, sem a pretensão de alcançá-la plenamente, mas de aproximar-se dela. Em contraste com as ideias adequadas e congruentes com a realidade, existem duas categorias principais de ideias que transcendem a situação: as ideologias e as utopias.

A ideologia e a utopia, na compreensão dada aos conceitos por Mannheim (1986), embora sejam distintas em sua relação com a sociedade são ideias produzidas socialmente e que transcendem a realidade:

As ideologias são as ideias situacionalmente transcendentes que jamais conseguem de facto a realização de seus conteúdos pretendidos. Embora se tornem com frequência motivos bem intencionados para a conduta subjetiva do indivíduo, seus significados, quando in- 
corporados efetivamente à prática, são, na maior parte dos casos, deformados (idem: 218).

Por sua vez, as utopias se bem que também transcendam a situação social, pois também orientam a conduta para elementos que a situação-tanto quanto se apresente em dada época - não contém, visam, por meio da contra-atividade, transformar a realidade histórica existente em outra realidade:

Consideramos utópicas todas as ideias situacionalmente transcendentes (não apenas projeções de desejos) que, de alguma forma, possuam um efeito de transformação sobre a ordem histórico-social existente (ibidem: 229).

Todos os períodos da história contiveram ideias que transcenderam a ordem existente, sem que exercessem contudo a função de utopias. Toda ordem de vida efetivamente operante contém concepções a que se pode designar de "transcendentes" ou "irreais" porque seus conteúdos jamais podem ser realizados nas sociedades em que existem e porque não se poderia viver e agir segundo eles dentro dos limites da ordem social existente. No entanto, são referidas como utópicas somente aquelas orientações que, transcendendo a realidade, tendem a se transformarem em conduta e a abalar, seja parcial ou totalmente, a ordem de coisas que prevalece no momento. As tendências não realizadas de uma época representam as suas necessidades e utopias.

As normas, valores e ideias são relativos ao pensamento e às experiências intersubjetivas. Da mesma forma, os conceitos também têm um caráter relacional. As mudanças de valores e ideologia acarretam percepções distintas também na compreensão dos conceitos de direita e de esquerda, que assumem significados diferentes em situações particulares. No que diz respeito a normas e valores, deve-se destacar a importância do contexto histórico e relacional para a validação da dicotomia esquerda-direita.

Bobbio (2006) assevera que a distinção entre ideologias políticas, como direita e esquerda, dependeria da realidade social e dos valores defendidos pela sociedade a cada momento. Entretanto, com base em argumentos históricos e sociológicos, o autor oferece subsídios que fundamentam as razões que justificam a permanência dessa distinção.

As alcunhas, segundo Bobbio, podem variar, mas a essência da dicotomia é incessante no debate político. O critério para a distinção seria, basicamen- 
7. Cf. Renata Florentino Faria Santos (2009), "Saindo de cena: Parlamentares que desistem da disputa eleitoral (19902006)", dissertação de mestrado, Departamento de Sociologia, Brasília: UnB: 71.

8. Desde as primeiras eleições para a Câmara dos Deputados com a implantação da Nova República, já em um quadro político

multipartidário - que incluiu o Partido dos Trabalhadores foram eleitos líderes da geração de 1968. Alguns deles não estavam na 52 a legislatura, como Vladimir Palmeira (eleito em duas legislaturas) e José Genoino (em cinco legislaturas). te, a percepção de cada indivíduo ou grupo sobre os valores da igualdade e da liberdade. Movimentos e doutrinas mais à esquerda seriam simultaneamente igualitários e libertários, e incluiriam praticamente todos os partidos social-democratas. Mais à direita se localizaria movimentos e doutrinas que seriam principalmente inigualitários.

Conforme poderá ser observado na descrição dos dados dos universitários da geração 68 que estão no Congresso Nacional, uma minoria participou do movimento estudantil ou de organizações políticas de esquerda. A maioria pertenceu a unidades geracionais distintas, com grande predomínio de indivíduos ausentes das manifestações estudantis naquele momento. Boa parte dos indivíduos da geração 68 que ascendeu ao poder após a transição democrática pertenceu na época a uma massa de jovens passivos em um dos períodos de maior efervescência política e cultural do país.

Na seção seguinte, apresentaremos a metodologia utilizada para a pesquisa, com posterior análise do comportamento legislativo atual da geração 68 .

\section{Metodologia}

O quadro no qual se estrutura a análise é a 52a legislatura na Câmara dos Deputados situa-se entre 2003 e 2007. A esquerda elegeu nessa legislatura 150 deputados federais, de um total de 513 , o que corresponde a $29,2 \%$ da casa. Foi a maior representação da esquerda desde a implantação da Nova República, em 1985 (Costa \& Queiroz, 2007; Anastasia \& Mágna, 2007).

Outro dado importante é a variação de idade desse contingente de deputados. Existe uma forte representação de uma esquerda mais nova, que entrou na universidade em meados e no final da década de 1970. Há uma esquerda intermediária, a da década de 1960, a qual pertence à geração 68. E tem também uma grande representação de uma esquerda mais antiga. $A$ média de idade dessa legislatura é de 51 anos, ${ }^{7}$ enquanto a da geração 68 é de 57, o que já dá aos representantes dessa geração uma posição de senioridade em relação ao perfil da Câmara de Deputados.

Para identificar os representantes da geração 68, procuramos, inicialmente, fazer um levantamento de todos os parlamentares nascidos entre 1945 e 1950 ou que estavam na universidade naquele ano emblemático, o lócus de conflitos e de manifestações do movimento estudantil. ${ }^{8} \mathrm{~A}$ fonte principal da pesquisa foi o Repertório biográfico, publicação da Câmara dos Depu- 
tados, de onde foram obtidas ainda as informações sobre o partido político, a universidade e a graduação cursada.

Desse filtro inicial foram localizados 130 deputados. Porém, como a idade é apenas uma questão formal e não apontaria para o aspecto mais sensível do fenômeno geração, decidimos realizar a análise empírica apenas com aqueles que estavam na universidade em 1968. Com isso, foram selecionados 60 parlamentares. ${ }^{9}$

Os parlamentares foram ainda divididos em dois grupos para a análise empírica. O objetivo foi identificar possíveis diferenças decorrentes do posicionamento político dos membros da geração 68. O primeiro grupo seriam as unidades geracionais: consideradas como participantes e não participantes do movimento estudantil. Participar do movimento estudantil - apesar de não ser o único fator determinante - significava, geralmente, atuar ativamente nas manifestações contra o regime. Traços, valores e concepções peculiares distinguiam o comportamento de um líder estudantil. O segundo grupo foi delineado a partir da ideologia político-partidária, com a tradicional classificação entre direita, esquerda e centro (Rodrigues, 2001).

O comportamento legislativo foi avaliado a partir da análise dos projetos de lei apresentados durante a Legislatura ${ }^{10}$ e das emendas individuais apresentadas ao orçamento de 2004, propostas em 2003, o primeiro ano da legislatura.

Os projetos de lei foram classificados em três categorias:

1. políticas igualitárias ou não igualitárias (Bobbio, 2006);

2. Abrangência nacional ou local, seguindo metodologia desenvolvida por Fabiano Santos (1995) $)^{11}$; e

3. Conteúdo (podendo versar sobre educação, saúde, reforma agrária, cidadania e meio ambiente).

As emendas orçamentárias foram classificadas também de acordo com sua abrangência, oferecendo benefícios concentrados ou dispersos, e com seu conteúdo, versando sobre aspectos de natureza social ou não social.

As políticas igualitárias e as emendas com conteúdo social estariam historicamente ligadas a temas como educação, saúde e trabalho (Bobbio, 2006). Segundo Bobbio,

9. O que teria acontecido com os outros 60 indivíduos da amostra inicial?

Ou estavam na universidade em um momento anterior ou posterior ou simplesmente não cursaram nenhuma faculdade. Um parlamentar importante que foi incluído na análise, mas que não estava na universidade nesse período, foi Fernando Gabeira. Apesar de participar do movimento

daquela geração contra o regime militar, Gabeira não pertencia ao movimento estudantil. No exílio, ele cursou antropologia, na Suécia, entre 1975 e 1979.

10. Para

parlamentares que não participaram da 52 a Legislatura, consideramos os projetos apresentados durante a última legislatura em que estiveram presente.

11. A tipologia da abrangência espacial foi fundamentada em trabalho de Fabiano Santos (1995), que propôs uma classificação com quatro dimensões para os projetos de lei apresentados.

Seriam elas:

a. transferência concentrada de recursos; 
b. transferência

dispersa;

c. regulação

concentrada; e, por

fim,

d. regulação

dispersa.

Foram utilizadas

apenas as categorias concentrada e dispersa, a partir da orientação dada por Santos.

\section{Quadro 1}

Classificação dos projetos de acordo com a tipologia de Bobbio

\begin{tabular}{l|l|l}
\hline \multicolumn{1}{c|}{ Classificação } & \multicolumn{1}{c|}{ Tipo } & \multicolumn{1}{c}{ Inclui } \\
\hline Políticas igualitárias & Direitos socia is & $\begin{array}{l}\text { Saúde, educação, trabalho, assistência } \\
\text { social. }\end{array}$ \\
\hline Políticas não igualitárias & $\begin{array}{l}\text { Projetos não vinculados a } \\
\text { direitos sociais }\end{array}$ & Economia, administração, homenagens \\
\hline
\end{tabular}

O igualitarismo não deve ser entendido como uma utopia da sociedade em que todos são iguais em tudo, mas como tendência, de um lado, a exaltar mais o que faz os homens iguais do que o que os faz desiguais, e de outro, em termos práticos, a favorecer as políticas que objetivam tornar mais iguais os desiguais (2006:125).

As políticas igualitárias seriam programaticamente de esquerda, e incluiriam ainda políticas redistributivistas, tais como distribuição de renda e políticas vinculadas à reforma agrária. Políticas com conteúdo historicamente vinculado à esquerda, foram incluídas ainda em políticas igualitárias projetos com forte ligação com o programa da social-democracia, como os relacionados à cidadania e ao meio ambiente (Giddens, 2000).

Por outro lado, políticas não igualitárias não seriam simplesmente aquelas que buscam estabelecer a desigualdade, mas simplesmente políticas que não têm por princípio uma maior igualdade entre os indivíduos. Essas são, basicamente, as propostas de cunho econômico ou administrativo. Lucia Avelar e Inês Walter (2008), a partir da classificação ideológica dos partidos proposta por Leôncio Rodrigues, citam os partidos de direita como sendo pertencentes à política tradicional, inerentemente clientelista, baseada principalmente na provisão de benefícios concentrados, e sem muita preocupação com questões sociais importantes para a mudança de status quo.

\section{O perfil social e político dos parlamentares da geração 68}

Apesar de as manifestações de 1968 terem ganhado mais força nas áreas de formação humanística (Foracchi, 1972: 13), os cursos de formação tradicionalmente mais conservadora - como engenharia, direito e economia - responderam pela formação de 49\% dos deputados da geração de 1968 que estavam no parlamento na 52a Legislatura, conforme pode ser observado nos dados da Tabela 1. 
Tabela 1

Formação universitária dos parlamentares (\% por grupo)

\begin{tabular}{lccc}
\hline Curso superior & Todos & Mov_est & Não_Movest \\
\hline Direito & $23(39)$ & $8(54)$ & $15(33)$ \\
Medicina & $11(19)$ & $2(14)$ & $9(20)$ \\
Engenharia & $10(16)$ & $0(0)$ & $10(21)$ \\
Ciências Humanas e Sociais & $6(11)$ & $2(14)$ & $4(8)$ \\
Economia, Administração e Ciências Contábeis & $5(9)$ & $0(0)$ & $4(8)$ \\
Matemática e Física & $2(4)$ & $1(7)$ & $1(2)$ \\
Agronomia & $2(3)$ & $1(7)$ & $2(4)$ \\
Geologia & $1(2)$ & $1(7)$ & $0(0)$ \\
\hline Total & $60(100)$ & $\mathbf{1 5 ( 1 0 0 )}$ & $\mathbf{4 5 ( 1 0 0 )}$
\end{tabular}

Nota: Ciências humanas e sociais inclui os cursos de filosofia, ciências sociais, geografia e história. A porcentagem com relação ao grupo está em parênteses.

Fonte: Repertório Biográfico (2003).

Talvez isso se reflita no total de parlamentares daquela geração que não participaram ativamente do movimento estudantil. Apenas $25 \%$, ou 15 do total de 60 , se envolveram ativamente nas discussões e manifestações do movimento estudantil. Boa parte dos indivíduos daquela geração que estavam na Legislatura em 2003 foi uma massa de jovens passivos em um dos períodos de maior efervescência política e cultural do país. Talvez esse perfil se reflita no padrão de comportamento político a ser observado.

Tabela 2

Parlamentares da geração 68 por partido político

\begin{tabular}{lccc}
\hline Partido & Todos & Mov_est & Não_Mov_est \\
\hline PMDB & $14(23)$ & $3(20)$ & $11(24)$ \\
PT & $13(22)$ & $6(40)$ & $7(16)$ \\
PSDB & $11(18)$ & $4(27)$ & $7(16)$ \\
PFL & $9(15)$ & $0(0)$ & $9(20)$ \\
Outros & $4(8)$ & $2(14)$ & $2(4)$ \\
PTB & $3(5)$ & $0(0)$ & $3(7)$ \\
PPB & $2(3)$ & $0(0)$ & $2(4)$ \\
PPS & $2(3)$ & $0(0)$ & $2(4)$ \\
PSB & $2(3)$ & $0(0)$ & $2(4)$ \\
\hline Total & $\mathbf{6 0 ( 1 0 0 )}$ & $\mathbf{1 5 ( 1 0 0 )}$ & $\mathbf{4 5 ( 1 0 0 )}$ \\
\hline
\end{tabular}

Nota: Em “Outros" estão Prona, PC do B, PMN e PST, com um parlamentar cada. A porcentagem em relação ao total do grupo está entre parênteses.

Fonte: Repertório Biográfico (2003). 
Com relação à distribuição partidária, cerca de três quartos dos parlamentares que estavam na universidade em 1968 pertencem à elite partidária, composta pelo PMDB, PSDB, PFL e PT, conforme apresenta a Tabela 2. Como foi mostrado por Guimarães (2002), a localização partidária é um dos elementos fundamentais para que parlamentares tenham condição de influenciar no processo político-decisório ou mesmo se tornarem líderes importantes. Para aqueles que participaram do movimento estudantil, estar na política como líder demandaria atuar em legendas com poder de agenda, capazes de orientar a ação do legislativo.

Porém, antes de inserir comentários mais conclusivos sobre as escolhas políticas dos indivíduos daquela geração, deve-se considerar a evolução histórica dos partidos no Brasil no período imediatamente anterior à redemocratização. O PMDB, por exemplo, tem, em seus primórdios, a oposição (mesmo que engessada) à ditadura, regime conservador e fundamentalmente de direita. O PT, por sua vez, foi fruto de movimentos da sociedade civil, com estrutura basilar fundada por trabalhadores urbanos de São Paulo. Ou seja: era um partido fundado sob uma ideologia intrinsecamente de esquerda. Muitos dos parlamentares atuais da geração 68 se inseriram nos partidos quando esses ainda não tinham o perfil atual, e podem ter contribuído decisivamente para que houvesse uma mudança e uma adaptação dos partidos ao atual contexto social e político.

Ao se considerar a atuação ou não no movimento estudantil em 1968, observa-se que $67 \%$ dos que participavam estavam, na 52 a Legislatura, no PSDB e, principalmente, no PT, partidos tradicionais da corrente social-democrata no Brasil. Nenhum dos parlamentares da amostra filiados a parti-

Figura 1

Parlamentares por ideologia partidária (\%)

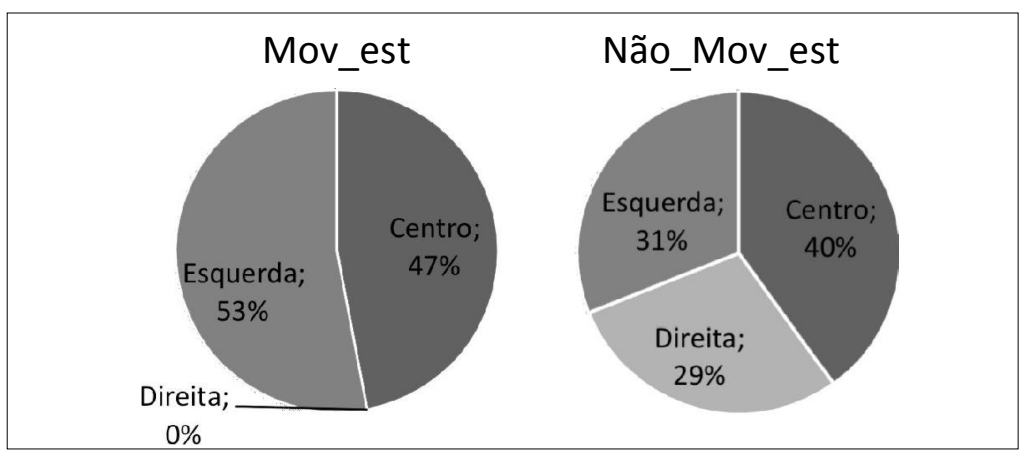


dos de direita - como o PFL (atual DEM) - participou do movimento estudantil em 1968, conforme pode ser observado na Figura 1.

Por outro lado, partidos historicamente de direita (como o PFL, o PTB e o PPB) respondem pela formação de $31 \%$ daqueles que não participaram do movimento estudantil, e que, portanto, ou não estavam nas manifestações ou simplesmente eram mais conservadores, sendo contrários aos meios utilizados naquele momento ou mesmo favoráveis ao regime político então em vigor. Citamos, como exemplo, o embate ideológico entre os estudantes da faculdade de filosofia da USP, contrários ao regime militar, e de direito do MacKenzie, favoráveis.

O cruzamento dos grupos com a ideologia política do partido elucida e resume bem os resultados observados acima. Dentre aqueles que não participaram do movimento estudantil, há uma divisão quase que simétrica entre os pensamentos atuais de direita, esquerda e centro. Por outro lado, parlamentares que participaram do movimento estudantil em 1968 são claramente identificados com partidos mais ao centro e à esquerda do espectro ideológico, como se observa na proporção dos deputados em partidos como o PT, o PSDB e o PMDB. Cabe destacar que esses três partidos, hoje em dia, assemelham-se muito em termos de ideologia política e econômica, tendo sido também fundados sob a ótica das ideias social-democratas.

Assim, é possível visualizar uma forte divisão ideológica entre os políticos atuais da geração 68. Aqueles que participaram do movimento estudantil, um grupo essencialmente político, seus valores comungaram com a adesão a partidos de esquerda ou de centro. De acordo com a Figura 1, 53\% dos parlamentares que participaram do movimento estudantil pertenciam a partidos de esquerda e $47 \%$ a partidos de centro no espectro ideológico. Aqueles que estiveram ausentes, naquele momento, do movimento estudantil, tenderam a apresentar um perfil ideológico bem mais difuso, liberal e conservador. Nesse caso, indivíduos que não participaram do movimento estudantil naquele período representam $69 \%$ dos parlamentares analisados.

De acordo com esse perfil político, seria possível identificar, por meio de dados empíricos, diferenças significativas no comportamento legislativo da geração 68 e suas distintas unidades geracionais? Ou seja: o que poderia distinguir de forma mais evidente a atuação dos parlamentares da geração 68 , a vivência comum no movimento estudantil ou a ideologia políticopartidária? 
Além de tentar discutir essa questão, o objetivo da próxima seção será traçar as diretrizes que orientam o comportamento político dos parlamentares, tentando identificar a herança política legada por aquela geração.

\section{Ideologia política e comportamento legislativo}

O contexto sociopolítico atual reforça a noção de que não existem mais as condições objetivas que cerca de quatro décadas atrás permitiram as manifestações e o pensamento revolucionários. Os valores individuais daqueles que permaneceram inseridos na política se diluíram entre partidos políticos com diversas ideologias, obedecendo a padrões de comportamento político específicos. De qualquer forma, nos dados a serem observados, esperava-se que houvesse diferenças no comportamento legislativo entre as distintas ideologias, confirmando o argumento de Bobbio (2006), assim como entre as duas unidades geracionais.

De uma forma geral, os parlamentares da geração 68 propuseram mais do que o dobro de projetos de lei com benefícios dispersos na sociedade, se comparado com os de abrangência concentrada, conforme mostra a Tabela 3. Por outro lado, o conteúdo dos projetos de lei daquela geração envolve muito mais questões não igualitárias. Entre os parlamentares que participaram do movimento estudantil, há duas vezes mais projetos de conteúdo de cunho econômico ou administrativo, quando comparado aos projetos vinculados a questões sociais.

Os dados mostram que participar das manifestações do movimento estudantil, com valores e concepções próprios, não significou uma atuação posterior com foco na defesa de projetos igualitários e com abrangência difusa na sociedade, como era esperado, tendo em vista o modelo de sociedade defendido naquele momento. A defesa de ideais de igualdade e justiça social não sensibilizaram mais os deputados que atuaram ativamente no movimento do que aqueles que não estavam presentes nas manifestações estudantis. O teste estatístico reportado mostra que a única diferença significativa foi em relação ao número de projetos de lei apresentados. Nesse caso, os deputados que atuaram no movimento estudantil são sensivelmente mais ativos.

A proporção de políticas igualitárias com relação à média - tanto para os que participaram como para os que não participaram - não indicou diferen- 
Tabela 3

Teste $t$ de diferença de médias

\begin{tabular}{|c|c|c|c|c|c|c|c|c|}
\hline & \multirow[b]{2}{*}{ Total } & \multicolumn{3}{|c|}{ Movimento estudantil } & \multicolumn{4}{|c|}{ Ideologia Partidária } \\
\hline & & Sim & Não & $x^{2}$ & Centro & Esquerda & Direita & $\chi^{2}$ \\
\hline № Obs. & 60 & 15 & 45 & $\begin{array}{ll}----- \\
\end{array}$ & 25 & 22 & 13 & $\begin{array}{ll}----- \\
\end{array}$ \\
\hline Projetos & 9,55 & 12,13 & 8,69 & $3,44^{*}$ & 8,76 & 10,5 & 9,46 & 1,04 \\
\hline Igualitários & 3,03 & 4,13 & 2,67 & 1,47 & 2,28 & 3,86 & 3,08 & $0,79 *$ \\
\hline Não igualitários & 6,5 & 8 & 6 & 2 & 6,48 & 6,64 & 6,31 & 0,33 \\
\hline Locais & 3 & 3,93 & 2,69 & 1,24 & 2,96 & 2,86 & 3,31 & $-0,44^{*}$ \\
\hline Nacionais & 6,57 & 8,20 & 6,02 & 2,18 & 5,8 & 7,64 & 6,23 & 1,41 \\
\hline Emendas & 13,35 & 15,13 & 12,76 & 2,38 & 11,32 & 16,36 & 12,15 & $4,21^{* *}$ \\
\hline Concentradas & 9,88 & 11,8 & 9,24 & 2,56 & 6,88 & 13,82 & 9 & $4,82^{*}$ \\
\hline Dispersas & 3,47 & 3,33 & 3,51 & $-0,18$ & 4,44 & 2,55 & 3,15 & $-0,61$ \\
\hline Social & 8,6 & 10,27 & 8,04 & 2,22 & 6,76 & 10,86 & 8,31 & 2,56 \\
\hline Não-Social & 4,7 & 4,87 & 4,64 & 0,22 & 4,56 & 5,36 & 3,85 & 1,52 \\
\hline
\end{tabular}

Nota: A diferença de médias para ideologia foi calculada entre deputados de partidos de esquerda e de direita.

Fonte: Elaboração própria a partir do banco de dados da Câmara dos Deputados.

${ }^{*} p>0,1 .{ }^{* *} p>0,05$.

ças significativas, uma vez que a diferença observada se deve essencialmente à diferença do total de projetos apresentados. A proporção média de projetos igualitários foi praticamente a mesma para os dois grupos. Da mesma forma, não houve diferença no comportamento das unidades geracionais com relação à abrangência dos projetos. A proporção de projetos de leis nacionais e locais foi praticamente a mesma para as duas categorias.

A comparação entre as médias dos projetos para as ideologias partidárias indicou resultados mais significativos. Deputados de esquerda propuseram, em média, $25 \%$ a mais de projetos de conteúdo social quando comparados a parlamentares de partidos de direita. Por outro lado, parlamentares de direita se concentram mais em políticas clientelistas, com benefícios concentrados em grupos específicos, aproximadamente $14 \%$ a mais do que parlamentares de partidos de esquerda.

A proposição de emendas orçamentárias apresentou uma tendência diversa para a amostra geral. Apesar de ter havido uma leve preponderância de políticas de abrangência concentrada, houve também um maior número de emendas com conteúdo social, ou seja, vinculadas à saúde, educação ou assistência social. 


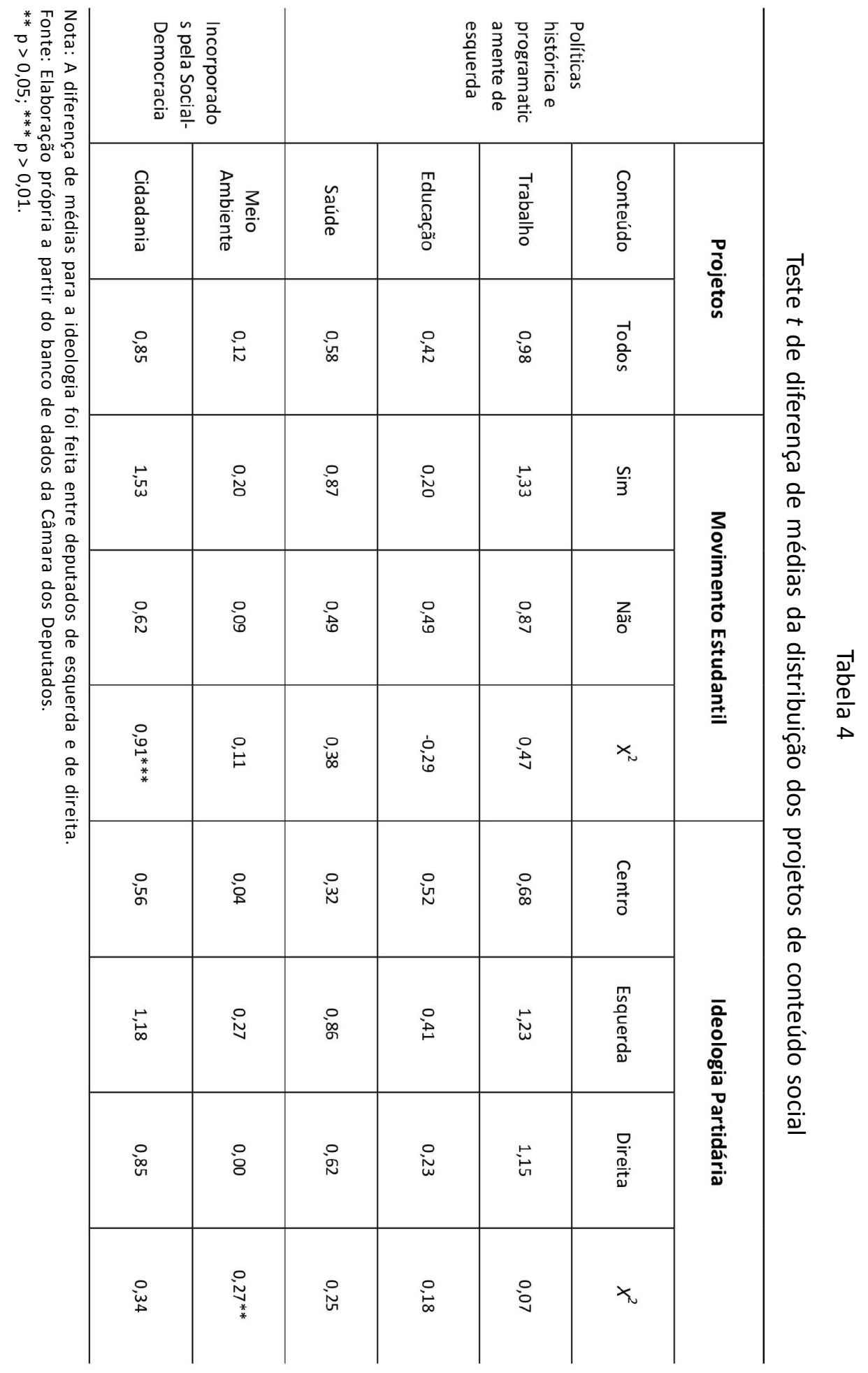


Com relação às unidades geracionais, foram observadas diferenças importantes apenas quanto à abrangência do benefício, não sendo significativas quanto ao conteúdo. Na Tabela 3, é possível verificar que parlamentares da geração 68 que atuaram no movimento estudantil, concentraram boa parte de seus esforços para o beneficiamento de localidades específicas, diferentemente do comportamento observado em relação aos projetos de lei. Assim, apesar de apresentarem um maior número de projetos de lei nacionais, quando a questão é orçamentária, ou seja, quando envolve a transferência direta de recursos, aqueles que participaram do movimento estudantil tendem a se concentrar na distribuição clientelista dos benefícios.

Quando considerada a ideologia partidária, a diferença mostrou-se significativa em relação ao número e à abrangência das emendas apresentadas. Parlamentares de esquerda propuseram, em média, 34,6\% a mais de emendas e $53 \%$ a mais com benefícios concentrados localmente. O resultado é diferente do observado nos projetos de lei e chega a ser surpreendente, uma vez que a natureza dos partidos de esquerda sempre foi mais universalista, enquanto os partidos de direita, pelo menos no Brasil, teriam uma tradição clientelista mais forte (Avelar, 2008).

Como forma de verificar algumas peculiaridades no comportamento legislativo da geração de 1968, analisou-se ainda a distribuição dos projetos igualitários de acordo com seu conteúdo. A Tabela 4 descreve os resultados obtidos.

Nos projetos de conteúdo igualitário, nota-se que há uma forte predominância de políticas vinculadas aos direitos trabalhistas e à cidadania, questões marcantes no processo de consolidação democrática no Brasil, onde foi grande a influência de organizações da sociedade civil e ideais social-democratas.

Para as distintas unidades geracionais, a diferença mais significativa foi observada em políticas vinculadas ao direito dos trabalhadores, ao meio ambiente e à cidadania, apesar de ter sido estatisticamente significante apenas para essa última. Parlamentares daquela geração que participaram do movimento estudantil propuseram quase duas vezes mais projetos vinculados aos direitos trabalhistas, duas vezes mais projetos com conteúdo ecológico, e mais do que o dobro de políticas de conteúdo vinculado a questões de cidadania.

A análise para a ideologia do partido não indicou diferenças significativas no conteúdo dos projetos de lei, apesar de haver uma leve tendência de 
parlamentares de partidos de esquerda serem mais sensíveis em praticamente todas as políticas de conteúdo igualitário. A diferença mais significativa foi com relação a políticas vinculadas ao meio ambiente, um tema ascendente na política, cujas origens remetem aos movimentos ambientalistas da década de 1960, e cuja ideia foi abraçada pela social-democracia.

\section{Considerações finais}

A partir dos resultados apresentados, nota-se que houve uma mudança ideológica e de comportamento político significativa dos indivíduos da geração 68. Essa mudança, muito provavelmente, foi adequada pelas novas regras na política brasileira e pelo novo contexto social. Por sua vez, as regras que regem a organização política do Congresso impedem de forma evidente que manifestações mais radicais se convertam em projetos de lei viáveis. Mesmo que alguns membros daquela geração tentem ver aprovados projetos com o conteúdo ideológico de outrora, se deparam com um sistema político predominantemente conservador, dificultando modificações no status quo (Figueiredo \& Limongi, 1999). É nesse cenário que devemos avaliar os resultados.

12. Em entrevista realizada com José Genoino, em junho de 2008, ficou clara a defesa de valores como a cidadania e o pluralismo quando Ihe foi perguntado sobre seus objetivos centrais na atuação política, aproximando-se de uma socialdemocracia reformista. Em extenso trabalho sobre a vida política de Genoino, Maria Francisca Pinheiro Coelho (2007) também levanta diversos aspectos relacionados com a mudança de foco na atuação política desse personagem, e de diversos outros líderes da geração 68.

A geração 68, mesmo com toda uma possível herança política daquele momento, não tem sua atuação vinculada estritamente a projetos sociais e de esquerda, embora se adeque a valores já buscados naquele momento. Com a redemocratização, muitos daquela geração chegaram ao poder, mas não procuraram fazer das eleições um instrumento de transformação social (Przeworski, 1989: 44).

Após a redemocratização, em meados da década de 1980, a sociedade brasileira orientou-se em torno de novas plataformas políticas, que, conjugadas com os ideais da ordem democrática então estabelecidos, passaram a ditar os discursos e as ações dos atores políticos. A transformação radical da sociedade deu lugar à conformação da cidadania, do pluralismo e de outros valores pós-materiais (Hirst, 1992). A defesa da cidadania e de outros ideais social-democratas passaram a dominar a agenda política nacional, obtendo o apoio dos principais líderes políticos. ${ }^{12}$

Devido aos obstáculos impostos pela organização formal do Legislativo, seria importante observar ainda o comportamento político dos membros daquela geração pela análise de seus discursos e votação nominal de alguns projetos importantes. Além disso, poderia ser feita uma comparação 
com o parlamento como um todo, no que diz respeito à produção legislativa, de forma a tornar possível considerar mais objetivamente a mudança de pensamento político verificada no horizonte de quatro décadas.

Julgar a atuação da geração 68 somente por meio da análise de suas proposições seria uma injustiça, assim como seria também julgá-la pelo que foi há quarenta anos. São tempos históricos distintos, com condições sociais e políticas também particulares. A ideologia e as utopias de outrora se reorientaram em torno de novos valores e perspectivas, e se adequaram a novos desafios e a um novo contexto sociopolítico e econômico.

Comparadas com a polarização do passado, as diferenças hoje entre as duas unidades da geração de 1968 são mais tênues, embora persista um núcleo comum de identidade principalmente entre os ex-militantes estudantis que orientam sua conduta por ideologias mais à esquerda e direcionam suas iniciativas parlamentares, particularmente os projetos de lei, para matérias de conteúdo mais igualitário. Esse núcleo comum, apesar de pouco sólido para as necessidades sociais do momento, ainda é um traço de distinção dessa unidade da geração 68. No entanto, os desafios do presente não moldam mais essa geração como no passado.

\section{Referências}

Anastasia, Fátima; Mágna, Inácio \& Melo, Carlos Ranulfo (2007). "Balanço da 52a Legislatura", in Plenarium, Ano 4, n. 4, Brasília: Câmara dos Deputados, Coordenação de Publicações.

Avelar, Lúcia \& Walter, Inês (2008). "Lentas mudanças: O voto e a política tradicional”, Opinião Pública, Vol. 14, n. 1, Campinas.

ARns, cardeal D. Paulo Evaristo (1985). Brasil nunca mais, Petrópolis: Vozes.

Bоввіо, Norberto (2006). Direita e esquerda: Razões e significados de uma distinção política, São Paulo: Editora Unesp.

Câmara dos Deputados (2002). Repertório Biográfico 52a Legislatura: 2003-2007, Volumes I e II, Brasília: Centro de Documentação e Informação.

CARdoso, Irene (2005). "A geração dos anos 60: O peso de uma herança”, Tempo Social, Vol. 17, n. 2, novembro. 
Coelho, Maria Francisco Pinheiro (2006). "Movimento estudantil marca a era dos extremos", Democracia Viva, Vol. 30, Rio de Janeiro.

— (2007). José Genoino: Escolhas políticas, São Paulo: Centauro.

Costa, Sylvio \& Quelroz, Antônio Augusto de (orgs) (2007). "Balanço da Legislatura 2003/2007", in O que esperar do novo Congresso: Perfil e agenda da Legislatura 2007/2011, Brasília: Diap, Congresso em Foco.

FigueIREDo, Argelina \& LIMONGI, Fernando (1999). Executivo e Legislativo na nova ordem constitucional, São Paulo: Editora FGV.

ForaCCHI, Marialice (1972). A juventude na sociedade moderna, São Paulo: Edusp.

Guimarães, Débora Messenberg (2002). A elite parlamentar no pós-Constituinte: Atores e práticas, São Paulo: Brasiliense.

Giddens, Anthony (2000). A terceira via: Reflexões sobre o impasse político atual e o futuro da social democracia, 3. ed., Rio de Janeiro: Record.

HIRST, Paul (1992). A democracia representativa e seus limites, Rio de Janeiro: Zahar Editores.

Mannheim, Karl (1986). Ideologia e utopia, Rio de Janeiro: Zahar Editores.

— (1983). "Funções das gerações novas", in: Luiz Pereira \& Marialice M. Foracchi, Educação e sociedade: Leituras de sociologia da educação, 11. ed., São Paulo: Ed. Nacional.

- (1951). "O problema das gerações", in idem, Sociologia do conhecimento, T. II, Porto: Rés.

-_ (1993). "El problema de las geraciones", Revista Española de Investigaciones Sociológicas (REIS), n. 62.

Mische, Ann (1997). "De estudantes a cidadãos", Revista Brasileira de Educação, Rio de Janeiro: Anped, n. 5.

Rodrigues, Leôncio (2002). Partidos, ideologia e composição social: Um estudo das bancadas partidárias na Câmara dos Deputados, São Paulo: Edusp. 
Rotman, Patrick (2008). A geração das barricadas. História viva - 1968 o ano zero de uma nova era, São Paulo: Duetto Editorial, Ano V, n. 54.

SAntos, Fabiano (1995). "Microfundamentos do clientelismo político no Brasil: 1959-1963", Dados, Vol. 38, n. 3, Rio de Janeiro.

SAntos, Renata Florentino de Faria (2009). "Saindo de cena: Parlamentares que desistem da disputa eleitoral (1990-2006)", dissertação de mestrado, Departamento de Sociologia, Brasília: UnB.

Weller, Wivian (2007). "Karl Mannheim: Um pioneiro da sociologia da juventude", trabalho apresentado no XIII Congresso Brasileiro de Sociologia, Recife, UFPE. 